\title{
LIGAND FIELD ANALYSIS OF METAL-OXYGEN INTERACTIONS-II. TRIS(OXALATO)CHROMATE(III)
}

\author{
SNEŽANA ZARIĆ and S. R. NIKETIĆ ${ }^{\star \dagger}$ \\ Department of Chemistry, Faculty of Science, University of Belgrade, \\ Studentski trg 16, P.O. Box 550, YU-11001 Belgrade, Yugoslavia
}

(Received 10 July 1991 ; accepted 1 August 1991)

\begin{abstract}
Ligand field analysis of $\left[\mathrm{Cr}(\mathrm{ox})_{3}\right]^{3-}$ has been performed using the angular overlap model (AOM) approach. The metal-oxygen interactions were treated as locally anisotropic. The Trees' correction and the explicit treatment of the second coordination sphere were included. A set of parameters was derived which reproduces both the quartet bands and sharp doublet lines. Relationships between structural and spectral data were investigated.
\end{abstract}

In the previous paper of this series ${ }^{1(a)}$ we have reported our studies on the tris(oxalato) cobaltate(III) ion in an attempt to examine the nature of metal-oxygen interactions, and to determine the extent of transferability of ligand-field parameters across the series of chromophores $\mathrm{MO}_{6-3 n} \mathrm{~N}_{3 n}, n=0,1,2$.

Already in the initial stages of that work we turned our attention also to chemically analogous chromium(III) complexes. In addition to offering the possibility to extend the range of systems on which we intended to investigate the above-mentioned hypotheses, $\left[\mathrm{Cr}(\mathrm{ox})_{3}\right]^{3-}$ presents a textbook example for ligand field studies. ${ }^{2,3}$ The latter is due to its rich and characteristic electronic absorption features.

It is therefore not surprising that $\left[\mathrm{Cr}(\mathrm{ox})_{3}\right]^{3-}$ has been widely investigated both experimentally and theoretically. Thus, while our work was in progress (parts are described in Ref. 1(b)) Schmidtke et al. have published an analysis of the quartet spectra ${ }^{4}$ and the doublet spectra ${ }^{5}$ of $\left[\mathrm{Cr}(\mathrm{ox})_{3}\right]^{3-}$. Also, among several examples in a review on sharp line spectra, Hoggard ${ }^{6}$ commented on the results of an AOM analysis of $\left[\mathrm{Cr}(\mathrm{Ox})_{3}\right]^{3-}$. The paper ${ }^{4}$ attempted to explain the observed large trigonal splitting of tris(oxalato) and tris(acetylacetonato) chromate(III) ions (the latter being of almost regular octahedral coordination) using the non-additive AOM approach due to the phase-coupling in

* Author to whom correspondence should be addressed. †E-mail address:〈xpmfh01@yubgss21.bitnet〉. the $\pi$-conjugated chelate rings. However, it was shown ${ }^{4}$ that such an approach is not required for the analysis of oxalato chelates.

\section{METHODS}

Computational procedures employed in this work are based on the AOM formalism ${ }^{7-10}$ and complete matrix diagonalization methods. ${ }^{11,12}$ They have been fully described previously. ${ }^{13}$ Extensions to the AOM treatment used in the study of $\left[\mathrm{Cr}(\mathrm{ox})_{3}\right]^{3-}$ were outlined in the preceeding paper. ${ }^{1(a)}$

\section{RESULTS AND DISCUSSION}

In the ligand field analysis of $\left[\mathrm{Cr}(\mathrm{ox})_{3}\right]^{3-}$ we have first optimized the parameters on quartet spectra. Then we have proceeded to fit the doublets spectra starting with those parameters. At this stage, we refined the parameters and introduced necessary extensions to the model in order to reproduce the spin-forbidden transitions and their splittings. This, eventually, led us to formulate the best parameter set and the conditions required to fit the whole optical spectrum of $\left[\mathrm{Cr}(\mathrm{ox})_{3}\right]^{3-}$.

\section{Quartet spectrum of $\left[\mathrm{Cr}(\mathrm{ox})_{3}\right]^{3-}$}

Development of parameters. As in the case of $\mathrm{Co}^{\mathrm{III}}$, ${ }^{1(\mathrm{a})}$ the basis for the ligand field analysis of $\left[\mathrm{Cr}(\mathrm{ox})_{3}\right]^{3-}$ was $\mathrm{X}$-ray structural data ${ }^{14}$ on the following five complexes: $\left(\mathrm{NH}_{4}\right)_{3}\left[\mathrm{Cr}(\mathrm{ox})_{3}\right]$. $2 \mathrm{H}_{2} \mathrm{O},{ }^{15} \mathrm{~K}_{3}\left[\mathrm{Cr}(\mathrm{ox})_{3}\right] \cdot 3 \mathrm{H}_{2} \mathrm{O},{ }^{16}\left(\mathrm{Me}_{4} \mathrm{~N}\right)_{3}\left[\mathrm{Cr}(\mathrm{ox})_{3}\right] \cdot$ 
Table 1. Selected structural data on $\left[\mathrm{Cr}(\mathrm{ox})_{3}\right]^{3-}$ complexes

\begin{tabular}{|c|c|c|c|c|c|c|c|}
\hline \multirow{2}{*}{$\begin{array}{c}\text { CSD } \\
\text { Refcode }^{a}\end{array}$} & \multirow{2}{*}{$\begin{array}{l}\text { Space } \\
\text { group }\end{array}$} & \multirow{2}{*}{\multicolumn{3}{|c|}{ Chelate angle $(\alpha)$}} & \multicolumn{3}{|c|}{ Average values } \\
\hline & & & & & $\alpha$ & $\theta$ & $\omega$ \\
\hline AMOXCR & $P-1$ & 84.835 & 84.221 & 80.036 & 82.36 & 56.31 & 50.35 \\
\hline CROXKH & $P 2_{\mathrm{J}} / c$ & 82.475 & 82.513 & 81.749 & 82.25 & 55.52 & 47.85 \\
\hline DITFER & $P-1$ & 82.427 & 82.352 & 82.201 & 82.33 & 57.08 & 52.51 \\
\hline SOXCRP & $C 2 / c$ & 82.428 & 82.799 & 82.244 & 82.49 & 55.99 & 49.79 \\
\hline FEPCOS & $P-1$ & 82.371 & 82.073 & 82.000 & 82.15 & 56.23 & 49.81 \\
\hline $\begin{array}{l}{ }^{a} \text { Refcodes: } \\
\text { AMOXCR- } \\
\text { CROXKH- } \\
\text { DITFER-1 } \\
\text { SOXCRP- } \\
\text { FEPCOS- }\end{array}$ & $\begin{array}{l}\left.\mathrm{I}_{4}\right)_{3}[\mathrm{Cr}(\mathrm{c} \\
\left.\mathrm{Cr}(\mathrm{ox})_{3}\right] \\
\mathrm{V})_{3}[\mathrm{Cr}(\mathrm{o} \\
\left.\mathrm{Cr}(\mathrm{ox})_{3}\right] \\
)_{3}[\mathrm{Cr}(\mathrm{ox}\end{array}$ & $\begin{array}{l}\left.\mathrm{x})_{3}\right] \cdot 2 \mathrm{H}_{2} \\
3 \mathrm{H}_{2} \mathrm{O},{ }^{16} \\
\left.{ }_{3}\right] \cdot \mathrm{H}_{2} \mathrm{O} \\
5 \mathrm{H}_{2} \mathrm{O},{ }^{18} \\
3] \cdot 3 \mathrm{H}_{2} \mathrm{O}\end{array}$ & $\begin{array}{l}0,{ }^{15} \\
{ }^{17}\end{array}$ & & & & \\
\hline
\end{tabular}

$\mathrm{H}_{2} \mathrm{O},{ }^{17} \mathrm{Na}_{3}\left[\mathrm{Cr}(\mathrm{ox})_{3}\right] \cdot 5 \mathrm{H}_{2} \mathrm{O},{ }^{18}$ and $\left(\mathrm{NH}_{4}\right)_{3}\left[\mathrm{Cr}(\mathrm{ox})_{3}\right] \cdot$ $3 \mathrm{H}_{2} \mathrm{O}^{19}{ }^{19}$ (Table 1), as well as the spectral data on $\left[\mathrm{Cr}(\mathrm{ox})_{3}\right]^{3-} .^{20-23}$

Commonly observed quartet spectra consist of two broad maxima at around $17.5 \mathrm{kK}\left({ }^{4} T_{2 g}\right)$ and $24.5 \mathrm{kK}\left({ }^{4} T_{1 g}\right)$. Trigonal splitting of the first spinallowed band is observed ${ }^{20,21,23}$ as ${ }^{4} A_{1}<{ }^{4} E_{\text {a }}$ in the monocrystal polarized spectra of $\mathrm{Cr}^{\text {III }}$ doped in $\mathrm{NaMg}\left[\mathrm{Al}(\mathrm{ox})_{3}\right] \cdot 9 \mathrm{H}_{2} \mathrm{O}$. Qualitatively similar splitting was inferred from the analysis of $\mathrm{CD}$ spectra. ${ }^{24,25}$ The symmetry-forbidden ${ }^{4} A_{2}$ component of the second $\left({ }^{4} T_{1 g}\right)$ band has been observed, ${ }^{4,21}$ due to vibronic coupling, as a weak band in polarized spectra.

Due to the fact that the crystal structure of $\mathrm{NaMg}\left[\mathrm{Al}(\mathrm{ox})_{3}\right] \cdot 9 \mathrm{H}_{2} \mathrm{O}$, the host lattice for all published solid-state electronic spectra of $\left[\mathrm{Cr}(\mathrm{ox})_{3}\right]^{3-}$, is not known, we have chosen an idealized average geometry of $\left[\mathrm{Cr}(\mathrm{ox})_{3}\right]^{3-}$ as a starting point for ligand-field analysis. The trigonal model structure was obtained by averaging over 12 oxalato rings from the four crystal structure determinations, and imposing the $C_{3}$ symmetry. This average structure is characterized by: $\alpha=82.315^{\circ}, \theta=56.22^{\circ}$, $\omega=50.06^{\circ}$, and $\psi=50.01^{\circ}$.

Preliminary calculations with different crystal structure geometries and idealized trigonal geometries showed that the positions and the order of trigonal components, as well as the extent of trigonal splitting, is dependent on small structural variations and on the presence or absence of a $C_{3}$ axis.

Therefore, we have set the following weighting criteria for parameter optimization. Highest relative weight was ascribed to the order of trigonal components of the "first" quartet band, taken as ${ }^{4} A_{1}<{ }^{4} E_{a}$, as found both in the solid-state optical spectra $^{20,21,23}$ and in the solution CD spectra. ${ }^{24,25}$
In the same way we have treated the position of the baricentre and the ${ }^{4} E_{b}$ component of ${ }^{4} T_{1 g}\left(O_{h}\right)$. The magnitude of trigonal splitting, the order of the components of the "second" quartet band, and the position of the ${ }^{4} A_{2}$ component of ${ }^{4} T_{1 g}\left(O_{h}\right)$ were given lower weight in the fitting procedure.

During the optimization the values of $F_{2}, F_{4}, e_{\sigma}$ and $e_{\pi}$ were allowed to vary. It was found that the results are quite insensitive with respect to the variation of the spin-orbit parameter. Therefore, its value was fixed at $115 \mathrm{~cm}^{-1}$ in agreement with previous studies. ${ }^{4}$ The position of the ${ }^{4} T_{2 g}$ baricentre is sensitive to $e_{\sigma}$ and $e_{\pi}$ parameters, and the order of trigonal components depends upon $e_{\pi}$. Second quartet band is dependent on $F_{2}$ and $F_{4}$ as well. The best parameter set for quartet spectra (Table 2) yielded for cubic crystal-field parameter,

Table 2. Comparison of experimental and calculated quartets spectra of $\left[\mathrm{Cr}(\mathrm{ox})_{3}\right]^{3-}$ complexes (in $\mathrm{cm}^{-1}$ )

\begin{tabular}{llll}
\hline \multicolumn{1}{c}{ Level } & \multicolumn{2}{c}{ Exptl } & Calc. $^{a}$ \\
\hline${ }^{4} A_{1}$ & $17630^{b}$ & $17608^{c}$ & 17710 \\
${ }^{4} E_{a}$ & 18060 & 18101 & 18020 \\
Baricentre & 17917 & 17937 & 17920 \\
${ }^{4} E_{b}$ & 23830 & 23856 & 23840 \\
${ }^{4} A_{2}{ }^{d}$ & 25160 & 25155 & $23910^{e}$
\end{tabular}

${ }^{a} F_{2}=1035 \mathrm{~cm}^{-1}, F_{4}=94 \mathrm{~cm}^{-1}, e(\sigma)=6570 \mathrm{~cm}^{-1}$, $e(\pi c)=650 \mathrm{~cm}^{-1}, e(\pi s)=0, \zeta=115 \mathrm{~cm}^{-1}$.

${ }^{b} \mathrm{NaMg}\left[\mathrm{Cr}(\mathrm{ox})_{3}\right] \cdot 9 \mathrm{H}_{2} \mathrm{O}$ at $25 \mathrm{~K} .{ }^{21}$

${ }^{c} 1.5 \%\left[\mathrm{Cr}(\mathrm{ox})_{3}\right]^{3-}$ in $\mathrm{NaMg}\left[\mathrm{Al}(\mathrm{ox})_{3}\right] \cdot 9 \mathrm{H}_{2} \mathrm{O}$ at $77 \mathrm{~K} .{ }^{23}$

${ }^{d}$ Forbidden transition.

eThis value shifts towards higher energies with the parameter set optimized on the whole spectrum and also with inclusion of the outer coordination sphere into AOM calculation (see Table 6). 
$10 \mathrm{Dq}, 18410 \mathrm{~cm}^{-1}$, and for Racah electrostatic parameters : $C=3290 \mathrm{~cm}^{-1}$ and $B=565 \mathrm{~cm}^{-1}$.

Effects of structural deformations. Three characteristic modes ${ }^{1}$ of trigonal deformations $(\theta=$ const., $\omega=$ const., and $\alpha=$ const.) were simu- lated on the idealized model of $\left[\mathrm{Cr}(\mathrm{ox})_{3}\right]^{3-}$. Their effect is shown on Fig. 1.

The average of 12 ox chelate rings from four crystal structures of $\left[\mathrm{Cr}(\mathrm{ox})_{3}\right]^{3-}$ with imposed $C_{3^{-}}$ axis can be classified as belonging to the $\theta=$ const.
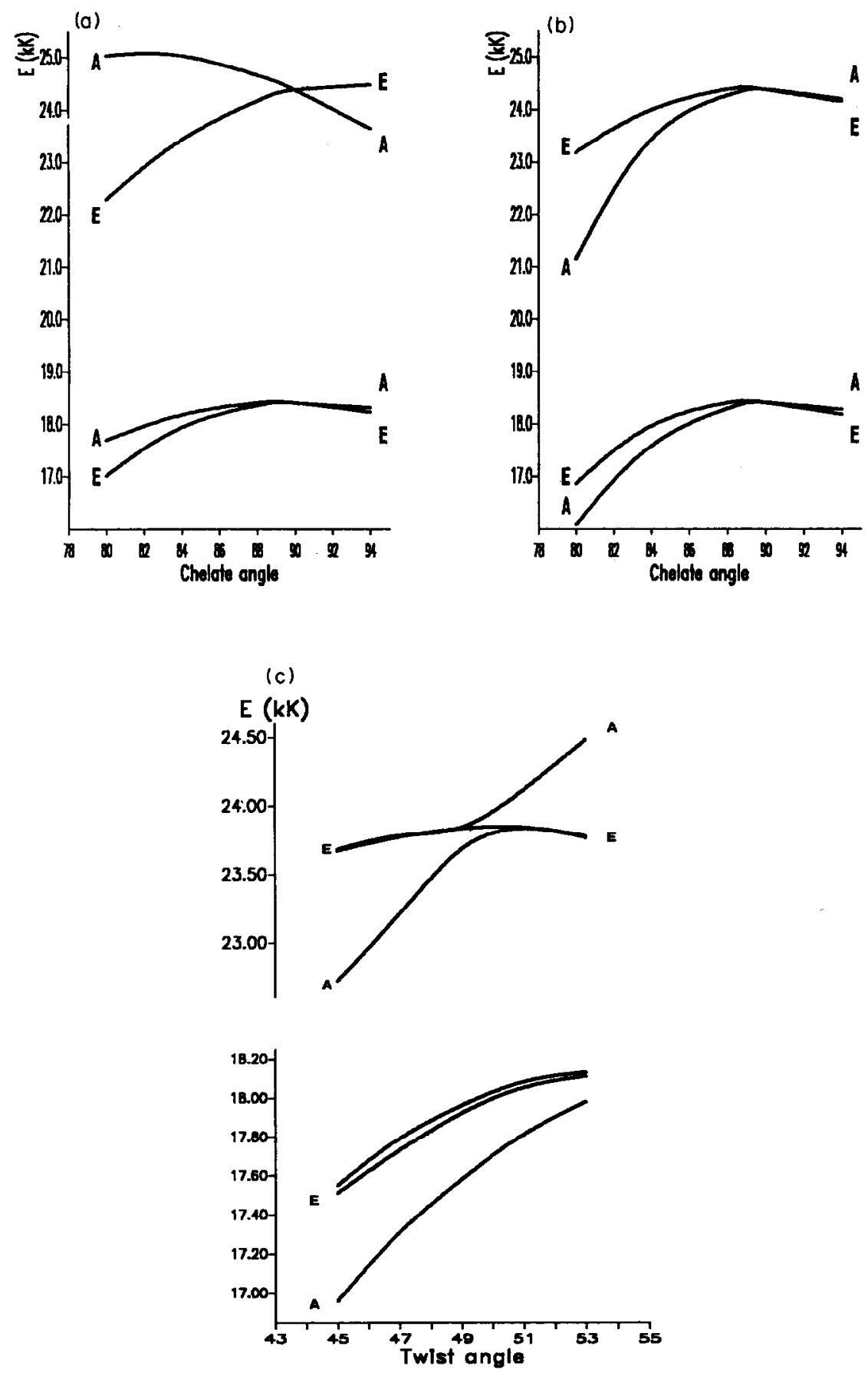

Fig. 1. The influence of characteristic modes of trigonal deformations on the calculated positions of trigonal components of the quartet bands. (a) Simultaneous change of $\alpha$ and $\theta$ at $\omega=60^{\circ}$. (b) Simultaneous change of $\alpha$ and $\omega$ at $\theta=54.74^{\circ}$. (c) Simultaneous change of $\theta$ and $\omega$ at $\alpha=82.31^{\circ}$. For all diagrams the best-fit parameter set for quartets spectra was used: $F_{2}=1035 \mathrm{~cm}^{-1}, F_{4}=$ $94 \mathrm{~cm}^{-1}, \zeta=115 \mathrm{~cm}^{-1}, e(\sigma)=6570 \mathrm{~cm}^{-1}$, and $e(\pi c)=650 \mathrm{~cm}^{-1}$. 
type of deformation. For that structure, analysis from Fig. 1 predicts the order ${ }^{4} A_{1}<{ }^{4} E_{a}$, which is actually obscrved both in polarized crystal spectra ${ }^{20,21,4}$ and in solution CD spectra. ${ }^{24,25}$

Another class of structural deformations is the one in which the trigonal symmetry is removed. In order to study the low symmetry deformations as found in actual crystal structures, we performed calculations on exact crystal structure geometries, on the same geometries with imposed $C_{3}$-symmetry, and with both the $C_{3}$-symmetry and with chelate rings constrained into planar conformations. The results (Table 3 ) indicate that both the baricentre positions and the order of trigonal components are indeed highly sensitive to these deformations.

Unfortunately, AOM results on actual crystal structure geometries are difficult to interpret because of extensive mixing of $A$ and $E$ components in both quartet bands $\left({ }^{4} T_{2 g}\right.$ and $\left.{ }^{4} T_{1 g}\right)$. If we assign symmetries to the trigonal components on the basis of clustering of the energy levels, we see that the experimentally established order $\left(A_{1}<E_{a}\right.$ $<E_{b}<A_{2}$ ) is not the same for all structures. The question as to whether these differences are due to trigonal deformations of $\left[\mathrm{Cr}(\mathrm{ox})_{3}\right]$ framework or to the lowering of symmetry (to $C_{1}$ ), or perhaps, to chelate ring puckering, is difficult to answer due to the impossibility to decouple different types of structural deformations which often show opposite effects on the energies of ligand-field states.

The order of trigonal components of the second quartet band $\left({ }^{4} T_{1 g}\right)$ appears to be most sensitive upon all kinds of structural deformations. In addition, this order for both quartet bands can be influenced by the changes in chelate ring conformation as shown in Fig. 2 for the skew-boat type $^{1(a)}$ of ring puckering.

Idealized structures derived from $\mathrm{X}$-ray structures (by imposing $C_{3}$ symmetry and chelate-ring planarity) generally show the "correct" order of LF

Table 3. Results of ligand-field analysis ${ }^{a}$ on crystal structures and idealized (trigonal) structures derived from X-ray data of $\left[\mathrm{Cr}(\mathrm{ox})_{3}\right]^{3-}$ complexes (in $\mathrm{cm}^{-1}$ )

\begin{tabular}{|c|c|c|c|c|c|}
\hline \multirow[b]{2}{*}{ Level } & \multicolumn{5}{|c|}{ Crystal structures $^{b}$} \\
\hline & DITFER & SOXCRP & AMOXCR & CROXKH & FEPCOS \\
\hline \multirow{3}{*}{${ }^{4} T_{2 g}$} & $17380^{c}$ & $17620^{c}$ & $17240^{c}$ & $17410^{c}$ & $17620^{c}$ \\
\hline & 17960 & 17870 & 17650 & 17630 & 17800 \\
\hline & 18690 & 17990 & 17940 & 17930 & 18020 \\
\hline \multirow{3}{*}{${ }^{4} T_{1 g}$} & $23600 E$ & $23620^{c}$ & $23400^{c}$ & $23390^{c}$ & $23600^{c}$ \\
\hline & & 23800 & 23550 & 23600 & 23800 \\
\hline & $24750 \mathrm{~A}$ & 23910 & 23760 & 23880 & 23910 \\
\hline \multirow[b]{2}{*}{ Level } & \multicolumn{5}{|c|}{ Idealized structures } \\
\hline & DITFER $^{d}$ & DITFER $^{e}$ & SOXCRP $^{d}$ & SOXCRP & $\mathrm{AMOXCR}^{d}$ \\
\hline \multirow[t]{2}{*}{${ }^{4} T_{2 g}$} & $18050^{f}$ & $18060^{f}$ & $17710 \mathrm{~A}$ & $17670 \mathrm{~A}$ & $17620 \mathrm{~A}$ \\
\hline & & & $17980 E$ & $18000 E$ & $17980 E$ \\
\hline \multirow[t]{2}{*}{${ }^{4} T_{1 g}$} & $23740 E$ & $23800 E$ & $23840^{r}$ & $23840^{f}$ & $23820^{f}$ \\
\hline & $24500 \mathrm{~A}$ & $24380 A$ & & & \\
\hline \multirow[b]{2}{*}{ Level } & \multicolumn{5}{|c|}{ Idealized structures } \\
\hline & $\mathrm{AMOXCR}^{e}$ & $\mathrm{CROXKH}^{d}$ & CROXKH & $\mathrm{FEPCOS}^{d}$ & FEPCOS $^{e}$ \\
\hline${ }^{4} T_{2 g}$ & $\begin{array}{l}17710 A \\
18010 E\end{array}$ & $\begin{array}{l}17480 \mathrm{~A} \\
17820 \mathrm{E}\end{array}$ & $\begin{array}{l}17430 \mathrm{~A} \\
17850 \mathrm{E}\end{array}$ & $17840^{f}$ & $\begin{array}{l}17650 A \\
17930 E\end{array}$ \\
\hline \multirow[t]{2}{*}{${ }^{4} T_{1 g}$} & $23870^{r}$ & $23490 \mathrm{~A}$ & $23430 \mathrm{~A}$ & $23650 E$ & $23750 E$ \\
\hline & & $23760 E$ & $23800 E$ & $24040 A$ & $23860 A$ \\
\hline
\end{tabular}

${ }^{a}$ Best-fit parameter set from Table 2.

${ }^{b}$ Structures defined in Table 1.

${ }^{c}$ Symmetry assignment was not possible due to extensive mixing of $A$ and $E$ functions.

All calculated values are given.

${ }^{d}$ Trigonal symmetry imposed.

eTrigonal symmetry and planar chelate rings.

${ }^{f}$ Baricentre. 

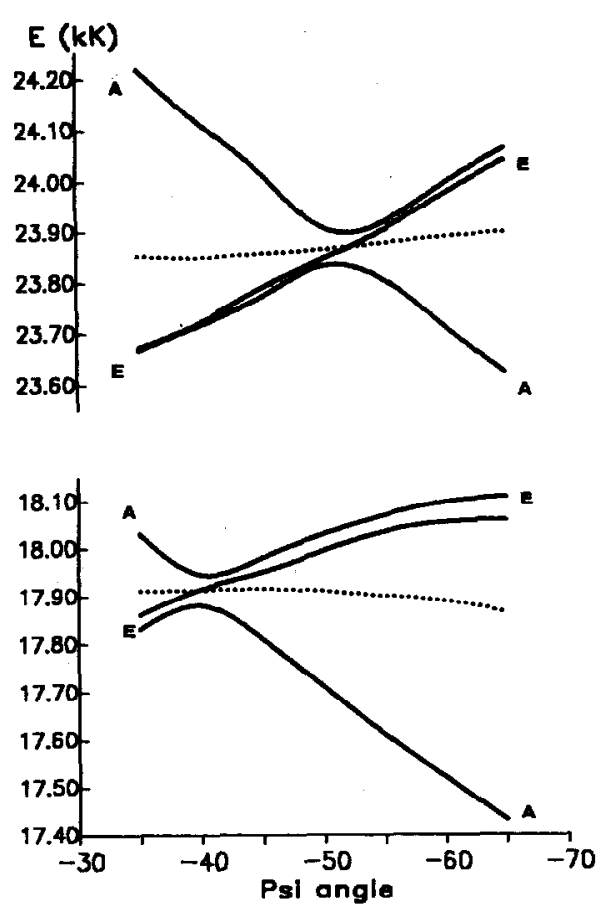

Fig. 2. The influence of the skew-boat type ${ }^{l(a)}$ of puckering of all three chelate rings in $\left[\mathrm{Cr}(\mathrm{ox})_{3}\right]^{3-}$ structure on the positions and splittings of quartets transitions. The bestfit parameter set for the whole spectrum was used: $F_{2}=1118.5 \mathrm{~cm}^{-1}, \quad F_{4}=71.7 \mathrm{~cm}^{-1}, \zeta=115 \mathrm{~cm}^{-1}$, $\alpha($ Trees $)=230 \mathrm{~cm}^{-1}, e(\sigma)=6540 \mathrm{~cm}^{-1}$, and $e(\pi c)=$ $600 \mathrm{~cm}^{-1}$.

levels $\left(A_{1}<E_{a}<E_{b}<A_{2}\right)$. An exception is CROXKH ${ }^{16}$ where it is reversed for ${ }^{4} T_{1 g}$. This is interpreted as being due to high relative degree of trigonal elongation of this structure (the lowest values of $\omega$ and $\theta$; Table 1). On the other hand, idcalized structures of DITFER ${ }^{17}$ and AMOXCR, ${ }^{15}$ which are trigonally compressedor, at least, less elongated than CROXKH (see Table 1) show the "correct" order of ligand-field levels.

The comparison of the present results with the calculations of Schmidtke et $a l .{ }^{4}$ is interesting. These authors ${ }^{4}$ have analysed $\left[\mathrm{Cr}(\mathrm{ox})_{3}\right]^{3-}$ on the basis of their electronic spectrum $[17.3,17.5,24.3$ and $24.6 \mathrm{kK}$ assigned to ${ }^{4} A_{\mathrm{l}},{ }^{4} E_{a},{ }^{4} E_{b}$ and ${ }^{4} A_{2}$, respectively] which is characterized by substantially smaller trigonal splittings compared to the previously reported spectra. ${ }^{20-23}$ Using their parametrization, with isotropic treatment of $\mathrm{Cr}-\mathrm{O}$ interactions, we obtained a good fit to the experimental spectrum when the actual X-ray geometry of CROXKH ${ }^{16}$ was used in the calculation. However, neither the anisotropic model nor the smoothing of the CROXKH structure into the $C_{3}$ geometry, could account for the above spectral data. ${ }^{4}$ On the other hand our parametrization based on the aniso- tropic AOM model, is able to reproduce well the experimental data on the solid state spectra, ${ }^{21,23}$ on the average geometry of all crystal structures, as well as on the smoothed geometries of most of the crystal structures except for the trigonally elongated CROXKH.

Therefore the proposition ${ }^{4}$ that $\left[\mathrm{Cr}(\mathrm{ox})_{3}\right]$ is subjected to a trigonal compression in the host lattice of $\mathrm{K}_{3}\left[\mathrm{Al}(\mathrm{ox})_{3}\right]$ is in agreement with our resultsbut only if other sources of structural deformations are disregarded (as is clearly evident from the $\alpha=$ const. diagram of Fig. 1). However, we argue that other types of deformations, such as symmetry lowering, and chelate-ring puckering, (the latter clearly evident from Fig. 2) are equally important, and that without further structural data on $[\mathrm{Cr} / \mathrm{Al}$ $\left.(\mathrm{ox})_{3}\right]$ systems it is not possible to extract unequivocal conclusions from the AOM results.

\section{Doublet spectrum of $\left[\mathrm{Cr}(\mathrm{ox})_{3}\right]^{3-}$}

Development of parameters. The lowest energy spin-forbidden transitions in $\left[\mathrm{Cr}(\mathrm{ox})_{3}\right]^{3-}$ can be detected even in aqueous solution spectra. ${ }^{2,26}$ However, only the low-temperature spectra of monocrystals, ${ }^{20,21}$ luminescent spectra, ${ }^{22}$ and recent excitation spectra $^{23}$ provide accurate experimental details to identify components of ${ }^{2} E,{ }^{2} T_{1 g}$, and ${ }^{2} T_{2 g}$ that arise from the lowering of symmetry of the chromophore and from spin-orbit coupling.

For the optimization of LF parameters we have, therefore, used the data from low-temperature luminescent $^{22}$ and excitation ${ }^{23}$ spectra of doublet transitions measured for $1 \%\left[\mathrm{Cr}(\mathrm{ox})_{3}\right]$ in $\mathrm{K}_{3}\left[\mathrm{Al}(\mathrm{Ox})_{3}\right] \cdot 9 \mathrm{H}_{2} \mathrm{O}$ host lattice, and the geometry corresponding to the crystal structure of $\mathrm{K}_{3}\left[\mathrm{Cr}(\mathrm{ox})_{3}\right]$. The inconsistency of such an approach may be due to the possible deformations of $\left[\mathrm{Cr}(\mathrm{ox})_{3}\right]$ moiety in the host lattice and to the temperature effects (room temperature X-ray study vs low temperature spectral study). However, Coleman ${ }^{23}$ assumed that differences between solid state spectra of pure $\mathrm{Cr}^{\text {III }}$ salts and their $1 \%$ solid solutions in isomorphous $\mathrm{Al}^{\mathrm{III}}$ salts are not significant.

The LF and AOM parameters optimized on quartets spectra do not reproduce the positions of doublets at all. But it has been shown before ${ }^{27}$ that it is impossible to fit spin-forbidden and spin-allowed transitions with the same interelectron repulsion parameters. Therefore, we first attempted to optimize $F_{2}$ and $F_{4}$ on doublets spectra keeping $e_{\varphi \lambda}$ parameters at their previously obtained (best-fit) values. This attempt failed also. Doublets spectra were indeed excellently reproduced (e.g. as in Table 4) only if all parameters were subjected to optimization. However, the parameter set that emerged 
from such a refinement (see Table 4) proved to be unacceptable for quartets spectra. The improved parameter set which could simultaneously account for quartet and doublet transitions was eventually obtained after introduction of the Trees' correction, as will be discussed below.

${ }^{2} E$ splitting. In spin-forbidden spectra of $\left[\mathrm{Cr}(\mathrm{ox})_{3}\right]^{3-}$ below $15 \mathrm{kK} \mathrm{a}{ }^{2} E$ transition is identified $^{21}$ with ${ }^{2} E$ splitting varying over two orders of magnitude ${ }^{22}$ in different $\left[\mathrm{Cr}(\mathrm{ox})_{3}\right]^{3-}$ salts (see Table 5). This splitting is ascribed ${ }^{22,23}$ to spin-orbit coupling and its relative magnitude to lattice effects.

A number of recent examples from the literature ${ }^{5,28-31}$ point to the difficulties in interpreting ${ }^{2} E$ splitting in $\mathrm{Cr}^{\mathrm{III}}$ complexes and to various attempts to reproduce it in LF analyses with the help of, e.g. Trees' correction, ${ }^{31}$ second coordination sphere, ${ }^{31}$ differential orbital expansion, ${ }^{27}$ symmetry limited $\pi$-orbital expansion, ${ }^{29}$ etc. but with limited success.

Using arbitrarily assumed values for electron repulsion parameters Hoggard $^{6}$ postulated that the ${ }^{2} E$ splitting has to be much larger than experimentally deduced ${ }^{22}$ and that the supposed ${ }^{2} E$ splitting reported by Coleman ${ }^{22}$ is in fact due to the existence of non-equivalent sites or to vibronic coupling. In contrast, our study showed that it is possible to account for the observed ${ }^{22}$ splitting of ${ }^{2} E$ within the present $A O M$ approach.

The splitting of ${ }^{2} E$ is very sensitive to the changes in the $e(\pi c)$ parameter. It is not at all sensitive to $F_{2}$ and $F_{4}$ which determine the difference between ${ }^{2} E$ and the other doublet states. Therefore it appears not to be necessary to fit $\Delta E\left({ }^{2} E-{ }^{2} T_{1 g}\right)$ difference with $e(\pi s)$ parameter as was done by Hoggard. ${ }^{6}$ The spin-orbit parameter does not have much influence

Table 4. Comparison of experimental and calculated doublets spectra of $\left[\mathrm{Cr}(\mathrm{ox})_{3}\right]^{3-}$ complexes $\left(\mathrm{in}^{-1} \mathrm{~cm}^{-1}\right.$

\begin{tabular}{cccc}
\hline Level & \multicolumn{2}{c}{ Exptl } & Calc $^{a}$ \\
\hline${ }^{2} E$ & \multicolumn{2}{c}{$14443^{b}$} & 14440 \\
& \multicolumn{2}{c}{14525} & 14527 \\
& $15187^{d}$ & $15210^{d}$ & 15171 \\
${ }^{2} T_{1 g}$ & 15272 & 15384 & 15264 \\
& 15305 & 15421 & 15319 \\
& $20508^{c}$ & $20522^{d}$ & 20491 \\
${ }^{2} T_{2 g}$ & 20596 & 20688 & 20588 \\
& 20628 & 20702 & 20772 \\
\hline
\end{tabular}

\footnotetext{
${ }^{a} F_{2}=1205 \mathrm{~cm}^{-1}, F_{4}=88.2 \mathrm{~cm}^{-1}, e(\sigma)=4020 \mathrm{~cm}^{-1}$, $e(\pi c)=650 \mathrm{~cm}^{-1}, e(\pi s)=0, \zeta=115 \mathrm{~cm}^{-1}$.

${ }^{b} 1 \%\left[\mathrm{Cr}(\mathrm{ox})_{3}\right]^{3-}$ in $\mathrm{K}_{3}\left[\mathrm{Al}(\mathrm{ox})_{3}\right] \cdot 3 \mathrm{H}_{2} \mathrm{O}$ at $77 \mathrm{K.}{ }^{22}$

${ }^{c} 1 \%\left[\mathrm{Cr}(\mathrm{ox})_{3}\right]^{3-}$ in $\mathrm{K}_{3}\left(\mathrm{Al}(\mathrm{ox})_{3}\right] \cdot 3 \mathrm{H}_{2} \mathrm{O}$ at $77 \mathrm{~K} .{ }^{23}$

${ }^{d} 1.5 \%\left[\mathrm{Cr}(\mathrm{ox})_{3}\right]^{3-}$ in $\mathrm{MaMg}\left[\mathrm{Al}(\mathrm{ox})_{3}\right] \cdot 9 \mathrm{H}_{2} \mathrm{O}$ at $77 \mathrm{~K} .{ }^{23}$
}

on the ${ }^{2} E$ splitting, so it was not optimized in this study. Trees' parameter, $\alpha$, which was introduced in order to correct the calculated position of ${ }^{2} T_{2 g}$, increases slightly the splitting of ${ }^{2} E$. Last, the skewboat type ${ }^{1}$ of chelate-ring puckering (but not the envelope type) also increases ${ }^{2} E$ splitting.

Calculated ${ }^{2} E$ splittings in the cases for which the $\mathrm{X}$-ray crystal structures were available, are given in Table 5. These results show that both the magnitude and the trend within the series of $\left[\mathrm{Cr}(\mathrm{ox})_{3}\right]^{3-}$ salts has been well reproduced. Lower calculated values for ${ }^{2} E$ splitting than the experimental ones ${ }^{22,23}$ are justifiable on the grounds that the present AOM treatment includes only the static contributions to splittings.

Markedly smaller ${ }^{2} E$ splitting obtained for the mean idealized structure (with $D_{3}$ symmetry) indicates that this spectral detail is particularly sensitive to symmetry lowering deformations such as those found in crystal structures of tris(oxalato) chromates(III). Another geometrical factor that presumably influences the ${ }^{2} E$ splitting is the trigonal compression. In the series of investigated $[\mathrm{Cr}$ $\left.(\mathrm{ox})_{3}\right]^{3-}$ structures the potassium salt CROXKH shows the highest trigonal elongation and the largest ${ }^{2} E$ splitting. It is smaller in the case of trigonally less-elongated SOXCRP and AMOXCR. In fact, the splitting is a result of various simultaneous structural deformations (including also the chelate-ring conformation) and is difficult to rationalize on the basis of individual contributions

Table 5. ${ }^{2} E$ Splittings in $\left[\mathrm{Cr}(\mathrm{ox})_{3}\right]^{3-}$ salts (in $\mathrm{cm}^{-1}$ )

\begin{tabular}{lcccc}
\hline Cation & Ref. $^{a}$ & Exptl & Calc. $^{b}$ & Calc. $^{c}$ \\
\cline { 3 - 5 } $\mathrm{NaMg}$ & 20 & 21 & $-{ }^{d}$ & - \\
$\mathrm{NaMg}$ & 21 & 20 & - & - \\
$\mathrm{NaMg}$ & 22 & 20 & - & - \\
$\mathrm{Na}_{3}$ & 22 & 34 & 25 & 24 \\
$\left(\mathrm{NH}_{4}\right)_{3}$ & 22 & 46 & 34 & 38 \\
$\left(\mathrm{NH}_{4}\right)_{3}$ & - & - & 27 & 31 \\
$\mathrm{~K}_{3}$ & 22 & 82 & 82 & 82 \\
$\left(\mathrm{Me}_{4} \mathrm{~N}\right)_{3}$ & - & - & 75 & 35 \\
$D_{3}{ }^{e}$ & - & - & 12 & 15 \\
\hline
\end{tabular}

${ }^{a}$ References are given for experimental $\Delta^{2} E$ reports only.

${ }^{b}$ Best parameter set for the whole spectrum: $F_{2}=$ $1118.5 \mathrm{~cm}^{-1}, F_{4}=71.7 \mathrm{~cm}^{-1}, e(\sigma)=6540 \mathrm{~cm}^{-1}, e(\pi c)$ $=600 \mathrm{~cm}^{-1}, \quad e(\pi s)=0, \quad \zeta=115 \mathrm{~cm}^{-1} . \quad \alpha$ (Trees) $=230 \mathrm{~cm}^{-1}$ (see Table 6).

${ }^{c}$ Best parameter set for doublets spectra: $F_{2}=1205$ $\mathrm{cm}^{-1}, F_{4}=88.2 \mathrm{~cm}^{-1}, e(\sigma)=4020 \mathrm{~cm}^{-1}, e(\pi c)=650$ $\mathrm{cm}^{-1}, e(\pi s)=0, \zeta=115 \mathrm{~cm}^{-1}$.

${ }^{d}$ Crystal structure not known.

${ }^{e}$ Structure of $\left[\mathrm{Cr}(\mathrm{ox})_{3}\right]$ averaged to $D_{3}$ symmetry. 
taken in turn. A good example is DITFER, which shows highest trigonal compression (Table 1) and yet it yields ${ }^{2} E$ splitting comparable to AMOXCR or SOXCRP. The explanation for such a result may be sought in different chelate-ring conformations between DITFER and AMOXCR or SOXCRP, as well as in different "degree of departure from $C_{3}$ symmetry" in addition to trigonal deformations.

${ }^{2} \mathrm{~T}_{1}$ and ${ }^{2} \mathrm{~T}_{2}$ states. Spin-forbidden transitions to the components of ${ }^{2} T_{1 g}$ and ${ }^{2} T_{2 g}$ were described by several authors ${ }^{20,21,23,26}$ who disagree in detailed assignments.

Our calculations show that $F_{2}$ and $F_{4}$ do influence the baricentres of ${ }^{2} T_{1}$ and ${ }^{2} T_{2}$, but that variations in $e_{\mathrm{c} \lambda}$ are particularly insignificant. Good fits to both ${ }^{2} T$ states are possible only with Trees' correction (as shown bclow). Splittings of ${ }^{2} T$ states are wellreproduced with the parameter set optimized on all doublets. Splittings are influenced by trigonal deformations (see Fig. 3), but again the trigonal elongation and chelate-ring puckering appear to be counteracting effects which cannot be disparted one from the other.

The splitting of ${ }^{2} T_{1}$ is insensitive towards both the changes in chelate-ring conformations and the lowering of the overall symmetry of $\left[\mathrm{Cr}(\mathrm{ox})_{3}\right]$. These deformations, however, influence the splitting of ${ }^{2} T_{2}$. Hoggard ${ }^{6}$ predicted a ${ }^{2} T_{2}$ splitting of about
$1000 \mathrm{~cm}^{-1}$, as opposed to the value estimated ${ }^{23}$ from the analysis of experimental spectra, which is about $120 \mathrm{~cm}^{-1}$ for the potassium salt. We were not able to obtain ${ }^{2} T_{2}$ splittings greater than 580 $\mathrm{cm}^{-1}$ with any sensible set of parameters (see below). Moreover, our lower limit to this value was about $180 \mathrm{~cm}^{-1}$ which is comparable to Coleman's findings. ${ }^{23}$

\section{Complete spectrum of $\left[\mathrm{Cr}(\mathrm{ox})_{3}\right]^{3-}$}

The failure of conventional AOM to account, with a unique set of parameters, both for the doublets and the quartets transitions in the optical spectra of $\mathrm{Cr}^{\mathrm{III}}$ complexes is well known: a number of suggestions on how to cope with this problem have appeared in the literature. 6,31

Another problem, which did not receive such attention, stems from the necessity to simultaneously fit data of different experimental accuracies : sharp doublet lines (which are sometimes not unambiguously assigned) and broad quartet bands (which are sometimes insufficiently resolved).

A single modification of AOM that significantly improved the overall fit was the introduction of Trees' correction in the form as described in the preceeding paper. ${ }^{l(a)}$ Trees' parameter $\alpha$ causes an
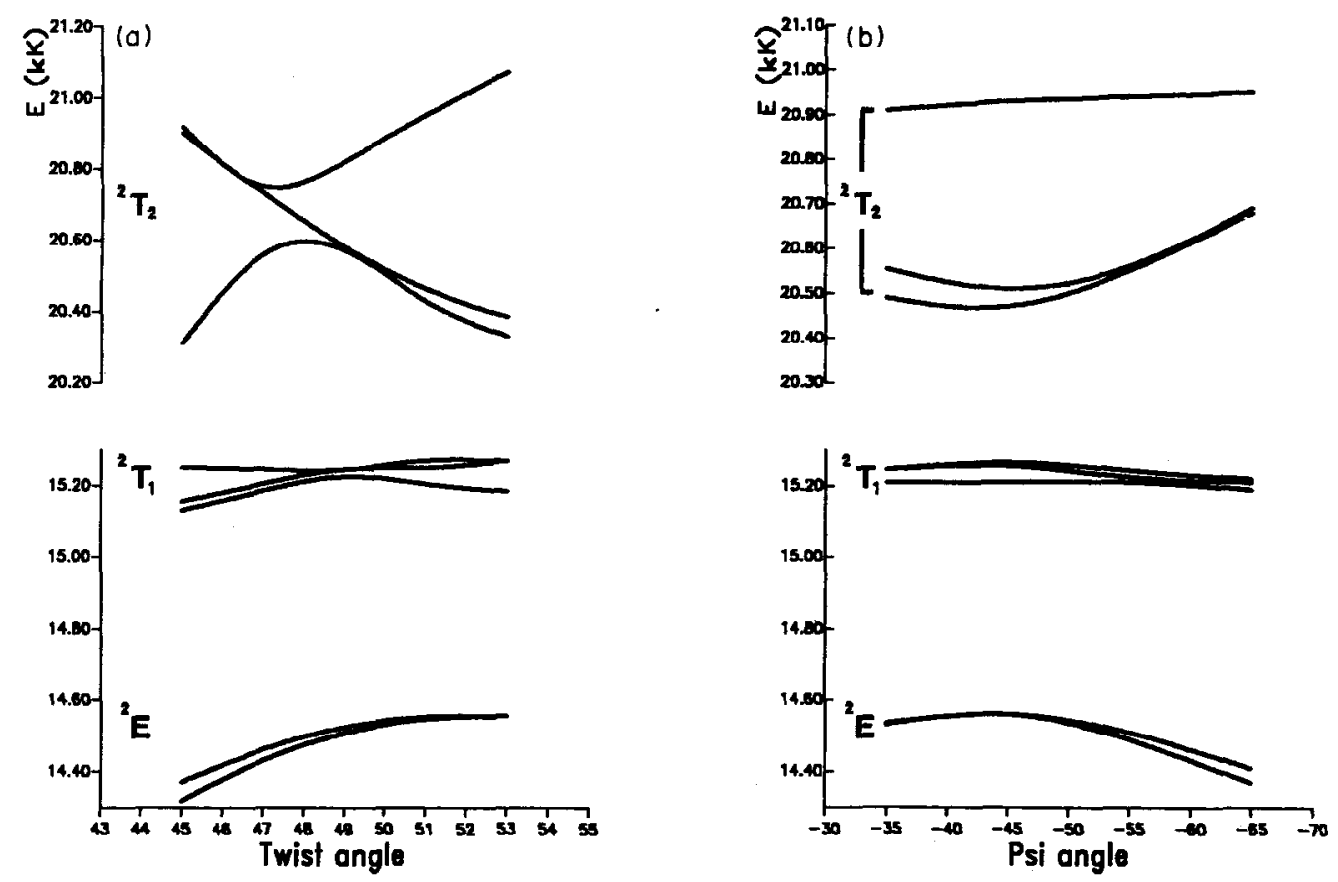

Fig. 3. The influence of trigonal deformations and chelate-ring conformation on the positions and splittings of doublets transitions. Left: Simultaneous change of $\theta$ and $\omega$ at $\alpha=82.31^{\circ}$. Right: The effect of skew-boat puckering of all three chelate rings in $\left[\mathrm{Cr}(\mathrm{ox})_{3}\right]^{3-}$ structure. For both diagrams the best-fit parameter set for the whole spectrum was used. $F_{2}=1118.5 \mathrm{~cm}^{-1}, F_{4}=71.7 \mathrm{~cm}^{-1}$, $\zeta=115 \mathrm{~cm}^{-1}, \alpha($ Trees $)=230 \mathrm{~cm}^{-1}, e(\sigma)=6540 \mathrm{~cm}^{-1}$, and $e(\pi c)=600 \mathrm{~cm}^{-1}$. 
increase in energies of low-lying doublet states, it does not influence the position of the first quartet $\left({ }^{4} T_{2 g}\right)$ but it reduces the energy of the second quartet state $\left({ }^{4} T_{1 g}\right)$. It also increases slightly the splitting of ${ }^{2} E$ and ${ }^{2} T_{1 g}$ and, most importantly, it decreases the difference $\Delta E\left({ }^{2} E-{ }^{2} T_{2 g}\right)$. Introduction of parameter $\alpha$, of course, requires the reoptimization of the other parameters. Thus, it calls for modification of electron repulsion parameters $\left(F_{2}\right.$ and $\left.F_{4}\right)$, and a slight decrease in $e(\pi c)$ in order to reproduce ${ }^{2} E$ splitting, the change of $e(\sigma)$ in order to reproduce the baricentre of ${ }^{4} T_{1 g}$, and readjustment of other parameters in order to improve the overall fit to the quartet transitions.

The optimized value for $\alpha$ (about $230 \mathrm{~cm}^{-1}$ ) is larger than the one used ${ }^{32,33}$ for the analysis of free $\mathrm{Cr}^{\mathrm{III}}$ ion spectra. However, similarly large values of Trees' parameter were suggested before ${ }^{6,31,34}$ in the case of $\mathrm{Cr}^{\mathrm{III}}$ complexes.

Table 6. Final results of ligand-field analysis on the complete spectrum of $\left[\mathrm{Cr}(\mathrm{ox})_{3}\right]^{3-}\left(\right.$ in cm $\left.\mathrm{cm}^{-1}\right)$

\begin{tabular}{ccccc}
\hline I evel & Expt $^{a}$ & \multicolumn{3}{c}{ Calc. $^{b}$} \\
\hline${ }^{2} E$ & 14443 & $14443^{c}$ & & $14332^{d}$ \\
& 14525 & 14525 & & 14493 \\
& 15187 & 15192 & & 15117 \\
${ }^{2} T_{1 g}$ & 15272 & 15215 & & 15201 \\
& 15305 & 15235 & & 15227 \\
& 20508 & 20510 & & 20452 \\
${ }^{2} T_{2 g}$ & 20596 & 20700 & & 20754 \\
& 20628 & 20750 & & 20873 \\
${ }^{4} T_{2 g}$ & $17630 A$ & $17580 A^{e}$ & $17540 E^{f}$ & $17077 A$ \\
& $18060 E$ & $17870 E$ & $17940 A$ & $17724 E$ \\
${ }^{4} T_{1 g}$ & $23830 E$ & $24030 E$ & $23860 E$ & $23695 E$ \\
& $25160 \mathrm{~A}$ & $24150 A$ & $24230 A$ & $24237 A$
\end{tabular}

${ }^{a}$ Doublets : $1 \%\left[\mathrm{Cr}(\mathrm{ox})_{3}\right]^{3-}$ in $\mathrm{K} 3\left[\mathrm{Al}(\mathrm{ox})_{3}\right] \cdot 3 \mathrm{H}_{2} \mathrm{O}$ at $77 \mathrm{~K}^{22,23}$ Quartets : $\mathrm{NaMg}\left[\mathrm{Cr}(\mathrm{ox})_{3}\right] \cdot 9 \mathrm{H}_{2} \mathrm{O}$ at $25 \mathrm{~K}^{.21}$

${ }^{b}$ Geometry of the CROXKH. ${ }^{16}$

${ }^{c} F_{2}=1118.5 \mathrm{~cm}^{-1}, F_{4}=72 \mathrm{~cm}^{-1}, e(\sigma)=6490 \mathrm{~cm}^{-1}$, $e(\pi c)=600 \mathrm{~cm}^{-1}, e(\pi s)=0, \zeta=115 \mathrm{~cm}^{-1}, \alpha($ Trees $)$ $=227 \mathrm{~cm}^{-1}$.

${ }^{d} F_{2}=1118.5 \mathrm{~cm}^{-1}, F_{4}=71.7 \mathrm{~cm}^{-1}, e(\sigma)=6540$ $\mathrm{cm}^{-1}, e(\pi c)=600 \mathrm{~cm}^{-1}, e(\pi s)=0, \zeta=115 \mathrm{~cm}^{-1}$, $\alpha$ (Trees) $=230 \mathrm{~cm}^{-1}$, together with 17 nearest neighbour atoms (5 potassium and 12 water oxygens) from the crystal lattice.

${ }^{e}$ Quartets were calculated with mean idealized geometry of all crystal structures. Agreement with experimental values is better than with crystal structure CROXKH [cf. note ${ }^{f}$ below].

${ }^{f}$ Results obtained on CROXKH with parameter set ${ }^{c}$ given in order to enable comparison with the parameter set ${ }^{d}$ in which the counterion interactions are included.
The final results are presented in Table 6. A somewhat eclectic nature of the data (Table 6) stemmed from the fact that it was necessary to combine spectral and structural information from various sources in a consistent way. Thus, the calculation with the best-fit parameter set (data column 2 of Table 6) was done on the crystal structure CROXKH for doublets and on the mean idealized geometry for quartets since the exact geometry corresponding to the quartets spectra is not known. Furthermore, the parameter set which included the counterion contributions, was applied onto CROXKH structure both for doublets and for quartets (data column 4 of Table 6). So, for the sake of comparison of the two parameter sets, calculated quartets spectra for CROXKH are also given (data column 3 of Table 6).

An attempt to include contributions to $A O M$ from the outersphere. Following Coleman's ${ }^{22}$ suggestion that the second coordination sphere should be considered when analysing the shifts and splittings of sharp doublet lines, we made an attempt to extend the present AOM treatment by including contributions from the counterions and oxygens from water molecules from crystal lattices of $\left[\mathrm{Cr}(\mathrm{ox})_{3}\right]^{3-}$ salts.

The smallest interatomic distance between the $\mathrm{Cr}^{\mathrm{III}}$ centre and a counterion or $\mathrm{H}_{2} \mathrm{O}$ in any of known crystal structures is greater than $4 \AA$. Therefore, interactions were treated as isotropic with $e(\pi c)=e(\pi s)=0$.

The value of the parameter $e(\sigma)$ for a counterion or water oxygen was taken to be inversely proportional to a power of the interatomic distance. $R^{-3}$ and $R^{-5}$ dependence was proposed by Hoggard, ${ }^{34}$ but $R^{-7}$ and $R^{-9}$ were also used. ${ }^{35,36}$ Our calculations were performed assuming $R^{-5}$ law. For the nearest water oxygen (approx. $4.2 \AA$ ) it gives $e(\sigma)$ of approx. $200 \mathrm{~cm}^{-1}$. For the positive potassium ion, in CROXKH ${ }^{16}$ we used $e(\sigma)$ parameters of similar magnitude and opposite sign, in line with general relations between AOM and point charge crystal-field parameters. ${ }^{37-39}$

These corrections increase splittings of all doublet states $\left({ }^{2} E,{ }^{2} T_{1 g}\right.$, and $\left.{ }^{2} T_{2 g}\right)$ as well as the trigonal splitting of ${ }^{4} T_{2 g}$, and lower the energies of all ligandfield states. Unfortunately, for certain combinations of additional parameters, inversions in the order of trigonal components of ${ }^{4} T_{1 g}$ states are observed. By and large, this increase in parameter space demonstrated the necessity for reoptimization of the entire set of parameters, reasserting that for such an endeavour one needs self-consistent sets of accurate structural and spectral data, which are not available at present. 
Acknowledgements-This work was supported by the Serbian Research Fund. Computer resources were generously made available by the Serbian State Institute of Statistics (RZS) through the Computer Laboratory of the Univeristy of Belgrade.

\section{REFERENCES}

1. (a) S. Zarić and S. R. Niketić, Polyhedron 1991, 10, 2665; (b) S. Zarić and S. R. Niketić, lst Yugoslav Conf. on Molecular Sciences, Zagreb, Yugoslavia, May 1986, p. 165 ; S. Zarić, N. Mitić and S. R. Niketić, 6th Yugoslav-Italian Crystallographic Conf., Pula, Yugoslavia, May 1989, Paper O24, p. S88; S. Zaric, M.Sc. Thesis, University of Belgrade (1990).

2. S. S. Eaton, T. D. Yager and G. R. Eaton, J. Chem. Educ. 1979, 56, 635.

3. W. F. Coleman, J. Chem. Educ. 1982, 59, 643.

4. M. A. Atanasov, T. Schonherr and H.-H. Schmidtke, Theor. Chim. Acta 1987, 71, 59.

5. T. Schonherr, J. Spanier and H.-H. Schmidtke, $J$. Phys. Chem. 1989, 93, 5969.

6. P. E. Hoggard, Coord. Chem. Rev. 1986, 70, 85.

7. C. E. Schaffer and C. K. Jorgensen, Math. fys. Medd. Dan. Vid. Selsk, 34, No. 13, (1965).

8. C. E. Schaffer, Struct. Bond. 1968, 5, 68.

9. C. E. Schaffer, Pure Appl. Chem. 1970, 24, 361.

10. C. E. Schaffer, Struct. Bond. 1973, 14, 69.

11. W. Urland, Chem. Phys. Letts 1977, 46, 457.

12. M. L. Ellzey Jr, Comput. Phys. Commun. 1975, 10, 133.

13. S. R. Niketić and W. Urland, Polyhedron 1987, 6, 947.

14. Cambridge Structural Databasc. For description sec, e.g. (a) F. H. Allen, S. Bellard, M. D. Brice, B. A. Cartwright, A. Doubleday, H. Higgs, T. Hummelnik, B. G. Hummelnik-Peters, O. Kennard, W. D. S. Motherwell, J. R. Rogers and D. G. Watson, Acta Cryst. 1973, B35, 2331 ; (b) F. H. Allen, O. Kennard and R. Taylor, Accts Chem. Res. 1983, 16, 146.
15. J. N. van Niekerk and F. R. L. Schoening, Acta Cryst. 1952, 5, 499.

16. D. Taylor, Aust. J. Chem. 1978, 31, 1455.

17. N. Bulc, L. Golic and J. Siftar, Vestn. Slov. Kem. Drus. 1985, 32, 221.

18. N. Bulc, L. Golic and J. Siftar, Vestn. Slov. Kem. Drus. 1982, 29, 211.

19. E. H. Merrachi, B. F. Mentzen and F. Chassagneux, Rev. Chim. Miner. 1986, 23, 329.

20. T. S. Piper and R. L. Carlin, J. Chem. Phys. 1960, 33, 608; 1961, 35, 1809.

21. O. S. Mortensen, J. Chem. Phys. 1967, 47, 4215.

22. W. F. Coleman, J. Luminesc. 1975, 10, 163.

23. W. F. Coleman, J. Luminesc. 1980, 22, 17.

24. R. D. Gillard, D. J. Shepherd and D. A. Tarr, $J$. Chem. Soc., Dalton Trans. 1976, 594.

25. K. R. Butler and M. R. Snow, J. Chem. Soc., Dalton Trans. 1976, 251.

26. R. W. Olliff, D. B. Rands and D. Shooter, Aust. J. Chem. 1974, 27, 2057.

27. W. M. Walace and P. E. Hoggard, Inorg. Chem. 1983, 22, 491.

28. C. D. Flint and A. P. Matthews, J. Chem. Soc, Farad. Trans. (2) 1973, 69, 419.

29. H.-H. Schmidtke, H. Adamsky and T. Schonherr, Bull. Chem. Soc. Japan 1988, 61, 59.

30. L. Dubicki and P. Day, Inorg. Chem. 1971, 10, 2043.

31. K.-W. Lee and P. E. Hoggard, Inorg. Chem. 1988, $27,907$.

33. J. Ferguson, Progr. Inorg. Chem. 1970, 12, 159.

34. P. E. Hoggard and K.-W. Lee, Inorg. Chem. 1988, 27, 2335.

36. C. Linares, A. Louat and M. Blanchard, J. Chem. Phys. 1982, 68, 453.

37. M. Kibler, G. Grenet and R. Chatterjee, J. Luminesc. 1979, 18/19, 609.

38. P. J. Steenkamp and J. W. Gonsalves, Aust. J. Chem. 1980, 33, 1705.

39. M. Kibler, Aust. J. Chem. 1982, 35, 231. 